


\title{
Investigating the Genetic Architecture of Non-Cognitive Skills Using GWAS-by-Subtraction
}

\author{
"It takes something more than intelligence to act intelligently." \\ - Fyodor Dostoyevksy, Crime and Punishment
}

Perline A. Demange ${ }^{1,2,3 *}$, Margherita Malanchini ${ }^{4,5,6 *}$, Travis T. Mallard ${ }^{6}$, Pietro Biroli ${ }^{7}$, Simon R. Cox $^{8}$, Andrew D. Grotzinger ${ }^{6}$, Elliot M. Tucker-Drob ${ }^{6,9}$, Abdel Abdellaoui ${ }^{1,10}$, Louise Arseneault ${ }^{5}$, Elsje van Bergen ${ }^{1,3}$, Dorret I. Boomsma ${ }^{1}$, Avshalom Caspi ${ }^{5,11-13}$, David Corcoran $^{13}$, Benjamin Domingue ${ }^{14}$, Kathleen M. Harris ${ }^{15}$, Hill F. Ip ${ }^{1}$, Colter Mitchell ${ }^{16}$, Terrie E. Moffitt ${ }^{5,11-13}$, Richie Poulton ${ }^{17}$, Joseph Prinz ${ }^{13}$, Karen Sugden ${ }^{11}$, Jasmin Wertz ${ }^{11}$, Benjamin Williams ${ }^{11}$, Eveline L. de Zeeuw ${ }^{1,3}$, Daniel W. Belsky ${ }^{18,19} \#$, K. Paige Harden ${ }^{6} \#$, Michel G. Nivard ${ }^{1} \#$

* contributed equally

\# Jointly supervised the work

\footnotetext{
${ }^{1}$ Department of Biological Psychology, Vrije Universiteit Amsterdam, The Netherlands

${ }^{2}$ Amsterdam Public Health Research Institute, Amsterdam University Medical Centers, Amsterdam, The Netherlands

${ }^{3}$ Research Institute LEARN!, Vrije Universiteit Amsterdam, The Netherlands

${ }^{4}$ Department of Biological and Experimental Psychology, Queen Mary University of London, UK

${ }^{5}$ Social, Genetic and Developmental Psychiatric Centre, Institute of Psychiatry, King's College

London, UK

${ }^{6}$ Department of Psychology, University of Texas at Austin, USA
} 
${ }^{7}$ Department of Economics, University of Zurich, Switzerland

${ }^{8}$ Lothian Birth Cohorts group, Department of Psychology, University of Edinburgh, UK

${ }^{9}$ Population Research Center, University of Texas at Austin, USA

${ }^{10}$ Department of Psychiatry, Amsterdam UMC, University of Amsterdam, Amsterdam, the Netherlands

${ }^{11}$ Department of Psychology \& Neuroscience, Duke University, Durham, NC, USA

${ }^{12}$ Department of Psychiatry and Behavioral Sciences, Duke University School of Medicine, Durham, $\mathrm{NC}, \mathrm{USA}$

${ }^{13}$ Center for Genomic and Computational Biology, Duke University, Durham, NC, USA

${ }^{14}$ Stanford Graduate School of Education, Stanford University, Palo Alto, CA, USA

${ }^{15}$ Carolina Population Center and Department of Sociology, University of North Carolina at Chapel Hill, Chapel Hill, NC, USA

${ }^{16}$ Institute for Social Research, University of Michigan, Ann Arbor, USA

${ }^{17}$ Department of Psychology and Dunedin Multidisciplinary Health and Development Research Unit, University of Otago, Otago, NZ

${ }^{18}$ Department of Epidemiology, Columbia University Mailman School of Public Health, New York, NY, USA

${ }^{19}$ Robert N. Butler Columbia Aging Center, Columbia University, New York, NY, USA

Supplementary Notes, Figures, and Tables can be found at this link https://www.dropbox.com/s/kbpzithnqr9w8ji/NonCog_GWAS supplment 20200330.zip?dl=0 


\begin{abstract}
Educational attainment (EA) is influenced by characteristics other than cognitive ability, but little is known about the genetic architecture of these "non-cognitive" contributions to EA. Here, we use Genomic Structural Equation Modelling and prior genome-wide association studies (GWASs) of EA $(\mathrm{N}=1,131,881)$ and cognitive test performance $(\mathrm{N}=257,841)$ to estimate SNP associations with EA variation that is independent of cognitive ability. We identified 157 genome-wide significant loci and a polygenic architecture accounting for 57\% of genetic variance in EA. Non-cognitive genetics were as strongly related to socioeconomic success and longevity as genetic variants associated with cognitive performance. Noncognitive genetics were further related to openness to experience and other personality traits, less risky behavior, and increased risk for psychiatric disorders. Non-cognitive genetics were enriched in the same brain tissues and cell types as cognitive performance, but showed different associations with gray-matter brain volumes. By conducting a GWAS of a phenotype that was not directly measured, we offer a first view of genetic architecture of non-cognitive skills influencing educational success.
\end{abstract}


Success in school - and in life - depends on skills beyond cognitive ability ${ }^{1-4}$. Randomized trials of early-life education interventions find substantial benefits to educational outcomes, employment, and adult health, even though the interventions have no lasting effects on children's cognitive functions ${ }^{5,6}$. These results have captured the attention of educators and policy makers, motivating growing interest in so-called "non-cognitive

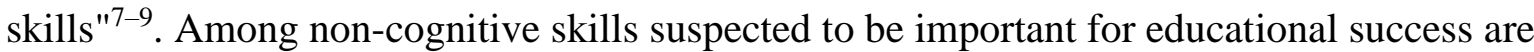
motivation, curiosity, persistence, and self-control ${ }^{1,10-13}$. However, questions have been raised about the substance of these skills and the magnitudes of their impacts on life outcomes $^{14}$.

Twin studies find evidence that non-cognitive skills are heritable $\mathrm{e}^{3,15-18}$. Genetic analysis could help clarify the contribution of these skills to educational attainment and elucidate their connections with other traits. But, a challenge to genetic research is a lack of consistent and reliable measurements of non-cognitive skills in existing genetic datasets ${ }^{19}$.

To overcome this challenge, we designed a GWAS of a latent trait, i.e. a trait not measured in any of the genotyped subjects ${ }^{20}$. We borrowed the strategy used in the original analysis of non-cognitive skills within the discipline of economics ${ }^{21,22}$ : We first isolated genetic variation in educational attainment that was not explained by cognitive skills. We then performed GWAS on this residual "non-cognitive" genetic variation in educational attainment. We conducted this analysis using Genomic Structural Equation Modeling $\left(\right.$ Genomic-SEM) ${ }^{23}$ applied to published GWAS summary statistics for educational attainment and cognitive performance ${ }^{24}$. Our analysis used these summary statistics to "subtract" genetic influence on cognitive performance from the association of each single-nucleotide polymorphism (SNP) with educational attainment. The remaining associations of each SNP with educational attainment formed a new GWAS of a non-cognitive skills phenotype that was never directly measured. We call this novel statistical approach GWAS-by-subtraction. 
We used results from the GWAS-by-subtraction of non-cognitive skills to conduct two sets of analysis. First, we conducted hypothesis-driven analyses using the phenotypic annotation approach ${ }^{25}$. We used genetic correlation and polygenic score analysis to test the hypothesis that non-cognitive skills influence educational and economic attainments and longevity and to investigate traits and behaviors that constitute non-cognitive skills. Second, we conducted hypothesis-free bioinformatic annotation analysis to explore the tissues, celltypes, and brain structures that might distinguish the biology of non-cognitive skills from the biology mediating cognitive influences on educational attainment.

\section{Results}

\section{GWAS-by-Subtraction Identifies Genetic Associations with Non-Cognitive Variance in}

\section{Educational Attainment}

The term "non-cognitive skills" was originally coined by economists studying individuals who were equivalent in cognitive ability, but who differed in educational attainment. ${ }^{22}$ Our analysis of non-cognitive skills was designed to mirror this original approach: We focused on genetic variation in educational outcomes not explained by genetic variation in cognitive ability. Specifically, we applied Genomic Structural Equation Modeling (Genomic-SEM) ${ }^{23}$ to summary statistics from GWASs of educational attainment ${ }^{24}$ and cognitive performance ${ }^{24}$. Both phenotypes were regressed on a latent factor representing genetic variance in cognitive performance (hereafter "Cog”). Educational attainment was further regressed on a second latent factor representing the residual genetic variance in educational attainment left over after regressing-out variance related to cognitive performance (hereafter "NonCog"). By construction, NonCog genetic variance was independent of $\operatorname{Cog}$ genetic variance $\left(r_{\mathrm{g}}=0\right)$. In other words, the NonCog factor represents genetic variation in educational attainment that is not accounted for by the $\operatorname{Cog}$ factor. These 
two latent factors were then regressed on individual SNPs, yielding a GWAS of the latent constructs NonCog and Cog. The model is illustrated in Figure 1.

The NonCog latent factor accounted for $57 \%$ of total genetic variance in educational attainment. Using the LD Score regression method ${ }^{26}$, we estimated SNP-heritability for NonCog to be $h^{2}{ }_{\text {NonCog }}=.0637$ (SE=.0021). After Bonferroni correction, GWAS of NonCog identified 157 independent genome-wide significant lead SNPs (independent SNPs defined as outside a $250 \mathrm{~Kb}$ window, or within a $250 \mathrm{~Kb}$ window and $\left.r^{2}<0.1\right)$. The results from the NonCog GWAS are graphed as a Manhattan plot in Figure 2. Results from Cog GWAS parallel the original GWAS of cognitive performance reported by Lee et al. (2018) ${ }^{24}$ and are reported in Supplementary Note 1 (Manhattan plot in Supplementary Figure 1). More information on the GWAS is reported in Supplementary Table 1, 2 and 3.

\section{Phenotypic Annotation Analysis Elucidates Behavioral, Psychological and Psychiatric Correlates of Non-Cognitive Skills Genetics}

Our phenotypic annotation analyses proceeded in two steps. First, we conducted polygenic score (PGS) and genetic correlation (rG) analysis to test if our GWAS-bysubtraction succeeded in identifying genetic influences that were important to educational attainment and also distinct from genetic influences on cognitive ability. Second, we conducted PGS and rG analyses to explore how NonCog related to a network of phenotypes that psychological and economic research has suggested might form the basis of noncognitive influences on educational attainment.

NonCog genetics are distinct from cognitive performance and are important to educational attainment, socioeconomic attainments, and longevity. To establish if the Genomic-SEM GWAS-by-subtraction succeeded in isolating genetic variance in education that was independent of cognitive function, we compared genetic associations of NonCog and 
Cog with educational attainment and cognitive test performance. Results for analysis of education and cognitive test phenotypes are graphed in Figure 3.

We conducted PGS analysis of educational attainment in the Netherlands Twin Register $^{27}$ (NTR), National Longitudinal Study of Adolescent to Adult Health ${ }^{28}$ (AddHealth), Dunedin Longitudinal Study ${ }^{29}$, E-Risk ${ }^{30}$, and Wisconsin Longitudinal Study ${ }^{31}$ (WLS) cohorts (meta-analysis $N=24,056$; cohorts descriptions in Supplementary Tables 4 \& 5 and

Supplementary Note 2). PGS effect-sizes were the same for NonCog and Cog (NonCog $\beta=.24(S E=.03), \operatorname{Cog} \beta=.24$ ( $S E=.02), p_{\text {diff }}=.702$, total; all PGS results are reported in Supplementary Tables 6 and 7). We conducted complementary genetic correlation analysis using Genomic SEM and GWAS summary statistics from a hold-out-sample GWAS of educational attainment (Supplementary Note 3). In this analysis, the genetic correlation of NonCog with educational attainment was stronger than the genetic correlation of $\operatorname{Cog}$ with educational attainment (NonCog $r_{g}=.71$ (SE=.02), $\operatorname{Cog} r_{g}=.57$ (SE=.02), $p_{\text {diff }}<.0001$; all genetic correlation results are reported in Supplementary Tables 8 \& 9).

We conducted PGS analysis of cognitive test performance in the NTR, Texas Twin Project $^{32}$, Dunedin, E-Risk, and WLS cohorts (combined N=11,351). Effect-sizes for NonCog PGS associations with IQ were smaller by half as compared to Cog PGS associations (NonCog $\beta=.17$ ( $S E=.02), \operatorname{Cog} \beta=.29$ ( $\left.S E=.03) ; p_{\text {diff }}<.0001\right)$. Additional PGS analysis of IQ subscales are reported in Supplementary Figure 2. We conducted complementary genetic correlation analysis using results from a published GWAS of childhood $\mathrm{IQ}^{33}$. Parallel to the PGS analysis, the NonCog genetic correlation with childhood IQ was smaller by more than half as compared to the $\operatorname{Cog}$ genetic correlation with childhood IQ (NonCog $r_{\mathrm{g}}=0.31$ $\left.(S E=.06), \operatorname{Cog} r_{\mathrm{g}}=0.75(S E=.08), p_{\text {diff_fdr }}<.0001\right)$. Of the total genetic correlation between childhood IQ and educational attainment, $31 \%$ of the variance was explained by NonCog and $69 \%$ by $\operatorname{Cog}$. 
We next examined downstream economic and health outcomes associated with greater educational attainment. ${ }^{34,35}$ In PGS analysis in the AddHealth and Dunedin cohorts (N=6,358), NonCog and Cog PGSs showed similar associations with occupational attainment

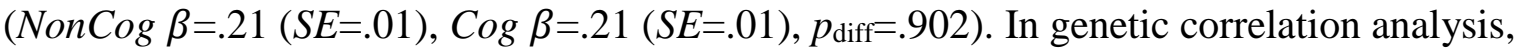
NonCog showed a similar relationship to income ${ }^{36}$ as $\operatorname{Cog}\left(N o n \operatorname{Cog} r_{\mathrm{g}}=.62\right.$, (SE=.04), Cog $\left.r_{\mathrm{g}}=.62(S E=.04), p_{\text {diff_fdr }}=.947\right)$ and a stronger relationship with neighborhood deprivation ${ }^{36}$ $\left(N o n \operatorname{Cog} r_{\mathrm{g}}=-.51(S E=.05), \operatorname{Cog} r_{\mathrm{g}}=-.32(S E=.04), p_{\text {diff_fdr }}=.001\right)$, a measure related to where a person can afford to live. In Genomic-SEM analysis, NonCog explained 53\% of the genetic correlation between educational attainment and income and $65 \%$ of the genetic correlation between educational attainment and neighborhood deprivation (Supplementary Table 10).

We conducted genetic correlation analysis of longevity based on GWAS of parental lifespan ${ }^{37}$. NonCog is more genetically associated with longevity than $\operatorname{Cog}\left(N o n \operatorname{Cog} r_{\mathrm{g}}=.37\right.$ $(S E=.03) ; \operatorname{Cog} r_{\mathrm{g}}=.27$ (SE=.03); $\left.p_{\text {diff_fdr }}=.024\right)$. In Genomic-SEM analysis, NonCog explained $61 \%$ of the genetic correlation between educational attainment and longevity.

In sum, NonCog and Cog genetics showed similar relationships with educational attainment and its long-term outcomes, despite NonCog genetic having a much weaker relationship to measured cognitive test performance than $\operatorname{Cog}$ genetics. These findings broadly support the hypothesis that non-cognitive skills distinct from cognitive abilities are an important contributor to success across the life course.

We next conducted a series of genetic correlation analyses to explore the network of phenotypes to which NonCog was genetically correlated. To develop understanding of the substance of noncognitive skills, we tested where in that network of phenotypes genetic correlations with NonCog diverged from genetic correlations with Cog. Our analysis was organized around four themes: decision making preferences, health-risk and fertility behaviors, personality traits, and psychiatric disorders. Results of genetic correlation analyses 
are graphed in Figure 4, and additionally in Supplementary Figure 3. Results are reported in Supplementary Table 9.

NonCog genetics were associated with decision-making preferences. In economics, non-cognitive influences on achievement and health are often studied in relation to decision-making preferences ${ }^{38-41}$. NonCog was genetically correlated with higher levels of comfort with risk-taking ${ }^{42}$ (risk tolerance $\left.r_{\mathrm{g}}=.10(S E=.03)\right)$ and willingness to forego immediate gratification in favor of a larger reward at a later time ${ }^{43}$ (delay discounting $r_{\mathrm{g}}=-.52$ $(S E=.08))$. In contrast, $C o g$ was genetically correlated with generally more cautious decisionmaking characterized by lower levels of risk tolerance $\left(r_{\mathrm{g}}=-.35(S E=.07), p_{\text {diff_fdr }}<.0001\right)$ and moderate delay discounting $\left(r_{\mathrm{g}}=-.10(S E=.02), p_{\text {diff_fdr }}=.082\right)$.

\section{NonCog genetics were associated with less risky health behavior and delayed} fertility. An alternative approach to studying non-cognitive skills in economics and other social sciences is to infer individual differences in non-cognitive skills from patterns of risk behavior. In genetic correlation analysis of obesity ${ }^{44}$, substance use ${ }^{42,45-48}$, and sexual behaviors and early fertility ${ }^{42,49,50}$, NonCog was consistently genetically correlated with less risk taking ( $r_{\mathrm{g}}$ range $\left..2-.5\right)$, with the exception that the $r_{\mathrm{g}}$ with alcohol use was not different from zero and $r_{\mathrm{g}}$ with cannabis use was positive. Genetic correlations for $\operatorname{Cog}$ were generally in the same direction but of smaller magnitude.

\section{NonCog genetics were associated with a broad spectrum of personality}

characteristics linked with social and professional competency. In psychology, noncognitive influences on achievement are conceptualized as personality traits, i.e. patterns of stable individual differences in emotion and behavior. The model of personality that has received the most attention in genetics is a five-factor model referred to as the Big-5. Genetic correlation analysis of the Big-5 personality traits ${ }^{51-53}$ revealed NonCog genetics were most strongly associated with Openness to Experience (being curious and eager to learn; $r_{\mathrm{g}}=.30$ 
$(S E=.04))$ and were further associated with a pattern of personality characteristic of changes that occur as people mature in adulthood ${ }^{54}$. Specifically, NonCog showed a positive $r_{\mathrm{g}}$ with Conscientiousness (being industrious and orderly; $r_{\mathrm{g}}=.13$ ( $\left.S E=.03\right)$ ), Extraversion (being enthusiastic and assertive; $\left.r_{\mathrm{g}}=.14(S E=.03)\right)$, and Agreeableness (being polite and compassionate; $r_{\mathrm{g}}=.14(S E=.05)$ ), and negative $r_{\mathrm{g}}$ with Neuroticism (being emotionally volatile; $\left.r_{\mathrm{g}}=-.15(S E=.04)\right)$. Genetic correlations of $\operatorname{Cog}$ with Openness to Experience and Neuroticism were similar to those for $\operatorname{Non} \operatorname{Cog}\left(p_{\text {diff_fdr-Openness }}=.040, p_{\text {diff_fdr-Neuroticism }}=.470\right)$. In contrast, genetic correlations of Cog with Conscientiousness, Extraversion, and Agreeableness were in the opposite direction $\left(r_{\mathrm{g}}=-.25\right.$ to $\left.-.12, p_{\text {diff_fdr }}<.0005\right)$. PGS analyses of personality traits were also performed and reported in Supplementary Table 7,

\section{Supplementary Figure 4 and Supplementary Note 4.}

\section{NonCog genetics were associated with higher risk for multiple psychiatric}

disorders. In clinical psychology and psychiatry, research is focused on mental disorders. Mental disorders are generally associated with phenotypic impairments in academic achievement and social role functioning, ${ }^{55,56}$ but positive genetic correlations with educational attainment and creativity have been reported for some disorders ${ }^{57,58}$. We therefore tested NonCog $r_{g}$ with psychiatric disorders based on published case-control GWAS $^{59-65}$. NonCog was associated with higher risk for multiple clinically-defined disorders including anorexia nervosa $\left(r_{\mathrm{g}}=.26(S E=.04)\right)$, obsessive-compulsive disorder $\left(r_{\mathrm{g}}=.31\right.$ $(S E=.06))$, bipolar disorder $\left(r_{\mathrm{g}}=.27(S E=.03)\right)$, and schizophrenia $\left(r_{\mathrm{g}}=.26(S E=.02)\right)$. Genetic correlations between $\operatorname{Cog}$ and psychiatric disorders were either much smaller in magnitude (anorexia nervosa $r_{\mathrm{g}}=.08(S E=.03), p_{\text {diff_fdr }}<.001$; obsessive-compulsive disorder $r_{\mathrm{g}}=.05$ $\left.(S E=.05), p_{\text {diff_fdr }}=.002\right)$ or in the opposite direction (bipolar disorder $r_{\mathrm{g}}=-.07(S E=.03)$, $p_{\text {diff_fdr }}<.001$; schizophrenia $\left.r_{\mathrm{g}}=-.22(S E=.02), p_{\text {diff_fdr }}<.001\right)$. Both NonCog and Cog showed 
negative genetic correlations with attention-deficit/hyperactivity disorder (NonCog $r_{\mathrm{g}}=-.37$ $\left.(S E=.03), \operatorname{Cog} r_{\mathrm{g}}=-.37(S E=.04), p_{\text {diff_fdr }}=.947\right)$.

In sum NonCog genetics were associated with phenotypes from economics and psychology thought to mediate non-cognitive influences on educational success. These associations contrasted with associations for Cog genetics, supporting distinct pathways of influence on achievement in school and later in life. Opposing patterns of association were also observed for psychiatric disorders, suggesting that the unexpected positive genetic correlation between educational attainment and mental health problems uncovered in previous studies ${ }^{58,66,67}$ arises from non-cognitive genetic influences on educational attainment.

\section{Biological Annotation Analyses Reveal Shared and Specific Neurobiological Correlates}

The goal of biological annotation is to elucidate molecular mechanisms mediating genetic influences on the phenotype of interest. Our biological annotation analysis proceeded in two steps. First, we conducted enrichment analyses to test whether genes specifically expressed in certain tissues, or cell types are enriched in terms of the proportion of total heritability they explain, and if the enriched tissues and cell-types differed between NonCog and $\operatorname{Cog}$. Second, we conducted genetic correlation analysis to explore which brain structures NonCog and $\operatorname{Cog}$ genetics related to and if there were specific structures showing differential genetic correlation with NonCog and $\operatorname{Cog}$.

NonCog and $C o g$ genetics were enriched in similar tissues and cells. We tested whether common variants in genes specifically expressed in 53 GTEx tissues ${ }^{68}$ or in 152 tissues captured in a previous aggregation of RNA-seq studies ${ }^{69,70}$ were enriched in their effects on $\operatorname{Cog}$ or NonCog. Genes predominantly expressed in the brain rather than peripheral tissues were enriched in both NonCog and Cog (Supplementary Table 11). 
To examine expression patterns at a more granular level of analysis, we used MAGMA $^{71}$ and stratified LD score regression ${ }^{72}$ to test enrichment of common variants in 265 nervous system cell-type-specific gene-sets ${ }^{73}$. In MAGMA analysis, common variants in 95 of 265 gene-sets were enriched for association with NonCog. The enriched cell-types were predominantly neurons $(97 \%)$, with enrichment most pronounced for telencephalonprojecting neurons, di- and mesencephalon neurons, and to a lesser extent, telencephalon interneurons (Supplementary Figure 5 and Table 13). Enrichment for $\operatorname{Cog}$ was similar to NonCog (correlation between Z-statistics Pearson's $r=.85$ ) and there were no differences in cell-type-specific enrichment, suggesting that the same types of brain cells mediate genetic influences on NonCog and Cog (Supplementary Figure 6). Stratified LDSC results were similar to results from MAGMA (Supplementary Note 5, Supplementary Figure 7,

\section{Supplementary Table 14).}

The absence of difference in cell-type specific enrichment is a somewhat surprising result given that NonCog and $\operatorname{Cog}$ are constructed to be genetically uncorrelated. We therefore used the TWAS/Fusion tool ${ }^{74}$ to conduct gene-level analysis. This analysis used summary statistics from eQTL studies and our GWAS to test association of expression levels for 5378 transcripts of brain-expressed genes with the latent traits NonCog and Cog. This analysis revealed a mixture of concordant and discordant gene effects on NonCog and Cog, consistent with the genetic correlation of zero (Supplementary Note 6, Supplementary Figure 8, and Supplementary Table 15).

\section{NonCog and $C o g$ genetics show diverging associations with total and regional} brain volumes. EA has previously been found to be genetically correlated with greater total brain volume $\mathrm{e}^{75,76}$. We therefore used a GWAS of regional brain volume to compare the $r_{\mathrm{g}}$ of NonCog and Cog with total brain volume and with 100 regional brain volumes (99 gray matter volumes and white matter volume) controlling for total brain volume (Supplementary 
Table 16) ${ }^{77}$. For total brain volume, genetic correlation was stronger for $\operatorname{Cog}$ as compared to $\operatorname{NonCog}\left(\operatorname{Cog} r_{\mathrm{g}}=.22(S E=.04), N o n \operatorname{Cog} r_{\mathrm{g}}=.07(S E=.03), p_{\text {diff }}=.005\right)$. Total gray matter volume, controlling for total brain volume, was not associated with either NonCog or Cog (NonCog: $\left.r_{\mathrm{g}}=.07(S E=.04) ; \operatorname{Cog}: r_{\mathrm{g}}=.06(S E=.04)\right)$. For total white matter volume, conditional on total brain volume, genetic correlation was weakly negative for NonCog as compared to $\operatorname{Cog}\left(N o n \operatorname{Cog} r_{\mathrm{g}}=-.12(S E=.04), \operatorname{Cog}\left(r_{\mathrm{g}}=-.01\right.\right.$ (SE=.04), $\left.p_{\mathrm{diff}}=.04\right)$.

NonCog was not associated with any of the regional gray-matter volumes after FDR correction. In contrast, $\operatorname{Cog}$ was significantly associated with regional gray-matter volumes for the bilateral fusiform, insula and posterior cingulate ( $r_{\mathrm{g}}$ range .11-.17), as well as left superior temporal $\left(r_{\mathrm{g}}=.11(S E=.04)\right)$, left pericalcarine $\left(r_{\mathrm{g}}=-.16(S E=.05)\right)$ and right superior parietal volumes $\left(r_{\mathrm{g}}=-.22(S E=.06)\right)($ Figure 5).

Finally, we tested genetic correlation of NonCog and Cog with white matter tract integrity as measured using diffusion tensor imaging $(\mathrm{DTI})^{78}$. Analyses included 5 DTI parameters in each of 22 white matter tracts (Supplementary Table 17). NonCog was positively associated with the mode of anisotropy parameter (which denotes a more tubular, as opposed to planar, water diffusion) in the corticospinal tract, retrolenticular limb of the internal capsule, and splenium of the corpus callosum (Figure 5). But all correlations were small $\left(.10<r_{\mathrm{g}}<.14\right)$, and we detected no genetic correlations that differed between NonCog and $\operatorname{Cog}$ (Supplementary Note 7).

\section{Discussion}

GWAS of non-cognitive influences on educational attainment (EA) identified 157 independent loci and polygenic architecture accounting for more than half the genetic variance in EA. In genetic correlation and PGS analysis, these non-cognitive (NonCog) genetics showed similar magnitude of associations with EA, economic attainment and 
longevity to genetics associated with cognitive influences on EA $(\operatorname{Cog})$. As expected, NonCog genetics had much weaker associations with cognition phenotypes as compared to Cog genetics. These results contribute new GWAS evidence in support of the hypothesis that heritable non-cognitive skills influence educational attainment and downstream life-course economic and health outcomes.

Phenotypic and biological annotation analyses shed light on the substance of heritable non-cognitive skills influencing education. Economists hypothesize that preferences that guide decision-making in the face of risk and delayed rewards represent non-cognitive influences on educational attainment. Consistent with this hypothesis, NonCog genetics were associated with higher risk tolerance and lower time discounting. These decision-making preferences are associated with financial wealth, whereas opposite preferences are hypothesized to contribute to a feedback loop perpetuating poverty ${ }^{79}$. Consistent with results from analysis of decision-making preferences, NonCog genetics were also associated with healthier behavior and later fertility.

Psychologists hypothesize that the Big Five personality characteristics of conscientiousness and openness are the two "pillars of educational success"2,3,80. Our results provide some support for this hypothesis, with the strongest genetic correlation evident for openness. But they also show that non-cognitive skills encompass the full range of personality traits, including agreeableness, extraversion, and the absence of neuroticism. This pattern mirrors the pattern of personality change that occurs as young people mature into adulthood $^{54}$. Thus, non-cognitive skills share genetic etiology with what might be termed as "mature personality". The absolute magnitudes of genetic correlations between NonCog and individual personality traits are modest. This result suggests that the personality traits described by psychologists capture some, but not all genetic influence on non-cognitive skills. 
Although the general pattern of findings in our phenotypic annotation analysis indicated non-cognitive skills were genetically related to socially desirable characteristics and behaviors, there was an important exception. Genetic correlation analysis of psychiatric disorder GWAS revealed positive associations of NonCog genetics with schizophrenia, bipolar disorder, anorexia nervosa, and obsessive-compulsive disorder. Previously, these psychiatric disorders have been shown to have a positive $r_{\mathrm{g}}$ with EA, a result that has been characterized as paradoxical given the impairments in educational and occupational functioning typical of serious mental illness. Our results clarify that these associations are driven by non-cognitive factors associated with success in education. These results align with the theory that clinically-defined psychiatric disorders represent extreme manifestations of dimensional psychological traits, which might be associated with adaptive functioning within the normal range $\mathrm{e}^{81-83}$.

Finally, biological annotation analyses suggested that genetic variants contributing to educational attainment not mediated through cognitive abilities are enriched in genes expressed in the brain as compared to other tissues in the body. Subsequent enrichment analysis overwhelmingly identified genetic variants in genes specifically expressed in neurons as compared to other cell types in the brain. Thus, even though NonCog and $\operatorname{Cog}$ were genetically uncorrelated, variants in the same neuron-specific gene-sets were enriched for both traits. We found some evidence of differences between NonCog and Cog in associations with brain structure: NonCog was less strongly associated with gray matter volumes as compared to $\operatorname{Cog}$. Moderate sample sizes in neuroimaging GWAS mean these results must be treated as preliminary, requiring replication with data from larger-scale GWAS of white-matter and gray-matter phenotypes. Overall, the limited differentiation of NonCog and Cog in biological annotation analyses focused at the levels of tissue and cell type highlights the need for tools to examine differences in the behaviors of genes within 
cells and, in the interim, the added value of phenotypic annotation analyses focused at the level of psychology and behavior.

We acknowledge limitations. Genomic-SEM analysis to isolate non-cognitive genetic influences on educational attainment relies on a statistical model of a complex developmental process. Cognitive and non-cognitive skills develop in interaction with one another. For example, the dynamic mutualism hypothesis ${ }^{84}$ proposes that non-cognitive characteristics shape investments of time and effort, leading to differences in the pace of cognitive development ${ }^{85,86}$. In Genomic-SEM analysis, the NonCog factor is, by construction, uncorrelated with adult cognition. Thus, the statistical model is an imperfect representation of etiology. Nevertheless, statistical separation of NonCog from $\operatorname{Cog}$, although artificial, allows us to test if heritable traits other than cognitive ability influence educational attainment and to explore what those traits may be. Our finding that NonCog genetics account for roughly half of all genetic variance in EA should motivate future longitudinal studies to collect repeated measures of cognitive and non-cognitive skills in order to study their reciprocal relationship across development ${ }^{87,88}$.

Our use of Genomic-SEM to perform GWAS-by-subtraction relied on published GWASs of adult cognitive performance and of educational attainment. Biases and limitations in these GWASs will also affect our results. For example, a large portion of data in the cognitive performance GWAS came from UK Biobank, which administered only a limited battery of cognitive tests. This limited battery could fail to capture genetic influences on some cognitive functions, resulting in incomplete separation of cognitive from non-cognitive genetics within the Genomic-SEM analysis. Genomic-SEM analysis of NonCog genetics using data from GWAS with more comprehensive cognitive testing is needed.

In the case of GWAS of educational attainment, the included samples were drawn mainly from Western Europe and the U.S., and participants completed their education in the 
late $20^{\text {th }}$ and early $21^{\text {st }}$ centuries. The phenotype of educational attainment reflects an interaction between an individual and the social system in which they are educated.

Differences across social systems, including education policy, culture, and historical context, may result in different heritable traits having influence on educational attainment ${ }^{89}$. As a result, the GWAS results for educational attainment and the Genomic-SEM results for noncognitive skills based on these results may not generalize beyond the times and places when and where GWAS samples were collected. Follow-up analysis in cohorts drawn from other contexts are needed to clarify how findings for NonCog genetics generalize.

Generalization of the NonCog factor is also limited by the homogeneity of ancestry in the educational attainment and cognitive performance GWASs. Analysis included only participants of European descent. Although this restricted sample is necessary given the lack of methods for integrating genome-scale genetic data across populations with different ancestries $^{90,91}$, it raises a potential threat to external validity. Analysis of (Non)Cog in nonEuropean populations should be a priority following either the conduct of GWAS in other ancestries or the refinement of methods to better integrate data across samples drawn from different ancestries.

Within the bounds of these limitations, results also illustrate how Genomic-SEM can be used to conduct GWAS of phenotypes not directly measured in large-scale databases, an application that might have broad utility beyond the genetics of educational attainment. Our analysis provides a first view of the genetic architecture of non-cognitive skills influencing educational success. These skills are central to theories of human capital formation within the social and behavioral sciences and are increasingly the targets of social policy interventions. Our results establish that non-cognitive skills are central to the heritability of educational attainment and illuminate connections between genetic influences on these skills and social and behavioral science phenotypes. 


\section{Methods}

\section{Meta-analysis of educational attainment GWAS}

We reproduced the Social Science Genetic Association Consortium (SSGAC) 2018 GWAS of educational attainment ${ }^{24}$ by meta-analyzing published summary statistics for $N=766,345$ (www.thessgac.org/data) with summary statistics obtained from 23andMe, Inc. $(\mathrm{N}=365,538)$. We included SNPs with sample-size $>500,000$ and MAF $>0.005$ in the 1000 Genomes reference set (10,101,243 SNPs). We did not apply genomic control, as standard errors of publicly available and 23andMe summary statistics were already corrected ${ }^{24}$. Metaanalysis was performed using METAL ${ }^{92}$.

\section{GWAS-by-subtraction}

The objective of our GWAS-by-subtraction analysis was to estimate, for each SNP, the association with educational attainment that was independent of that SNP's association with cognition (hereafter, the NonCog SNP effect). We used Genomic-SEM ${ }^{23}$ to analyze GWAS summary statistics for the educational attainment and cognitive performance phenotypes in the SSGAC's 2018 GWAS (Lee et al. 2018 24 ). The model regressed the educational-attainment and cognitive-performance summary statistics on two latent variables, Cog and NonCog (Figure 1). Cog and NonCog were then regressed on each SNP in the genome. This analysis allowed for two paths of association with educational attainment for each SNP. One path was fully mediated by $\operatorname{Cog}$. The other path was independent of $\operatorname{Cog}$ and measured the non-cognitive SNP effect, NonCog. To identify independent lead hits with $p$ $<5 \mathrm{e}-8$ (the customary p-value threshold to approximate an alpha value of 0.05 in GWAS), we pruned the results using a radius of $250 \mathrm{~kb}$ and an LD threshold of $\mathrm{r}^{2}<0.1$ (Supplementary Tables 1 to 3). 


\section{Genetic correlations}

We use Genomic-SEM to compute genetic correlations of Cog and NonCog with other education-linked traits for which well-powered GWAS data were available (SNP- $h^{2}$ zscore $>2$; Supplementary Table 8) and to test if genetic correlations with these traits differed between Cog and NonCog. Specifically, models tested the null hypothesis that trait genetic correlations with $\operatorname{Cog}$ and NonCog could be constrained to be equal using a chisquared test with FDR adjustment to correct for multiple testing. The FDR adjustment was conducted across all genetic correlation analyses reported in the article excluding the analyses of brain volumes described below. Finally, we used Genomic-SEM analysis of genetic correlations to estimate the percentage of the genetic covariance between educational attainment and the target traits that was explained by $\operatorname{Cog}$ and NonCog using the model illustrated in Supplementary Figure 9.

\section{Polygenic score analysis}

Polygenic score analyses were conducted in data drawn from six population-based cohorts from the Netherlands, the U.K., the U.S., and New Zealand: (1) the Netherlands Twin Register (NTR) $)^{27,93}$, (2) E-Risk ${ }^{30}$, (3) the Texas Twin Project ${ }^{32}$, (4) the National Longitudinal Study of Adolescent to Adult Health (AddHealth) ${ }^{28,94}$, dbGaP accession phs001367.v1.p1; (5) Wisconsin Longitudinal Study on Aging (WLS) ${ }^{31}$, dbGaP accession phs001157.v1.p1; and (6) the Dunedin Multidisciplinary Health and Development Study ${ }^{29}$. Supplementary Tables 4 and 5 describe cohort-specific metrics, Supplementary Note 2 gives a short description of the cohorts' populations and recruitment. Polygenic scores were computed based on weights derived using the LD-pred ${ }^{95}$ software with an infinitesimal prior and the 1000 Genomes phase 3 sample as a reference for the LD structure. LD-pred weights were computed in a 
shared pipeline to ensure comparability between cohorts. Each outcome (e.g., IQ score) was regressed on the Cog and NonCog polygenic scores and a set of control variables (sex, 10 principal components derived from the genetic data and, for cohorts in which these quantities varied, genotyping chip and age). In cohorts containing related individuals, nonindependence of observations from relatives were accounted for using mixed linear models (MLM), generalized estimation equations (GEE), or by clustering of standard errors at the family level. We used a random effects meta-analysis to aggregate the results across the cohorts. This analysis allows a cohort-specific random intercept. Individual cohort results are in Supplementary Table 6 and meta-analytic estimates in Supplementary Table 7.

\section{Biological annotation}

Enrichment of tissue-specific gene expression. We used gene-sets defined in Finucane et al. $2018^{96}$ to test for the enrichment of genes specifically expressed in one of 53 GTEx tissues ${ }^{68}$, or 152 tissues captured by the Franke et al. aggregation of RNA-seq studies ${ }^{69,70}$. This analysis seeks to confirm the role of brain tissues in mediating $\operatorname{Cog}$ and NonCog influences on educational attainment. The exact analysis pipeline used is available online (https://github.com/bulik/ldsc/wiki/Cell-type-specific-analyses).

Enrichment of cell-type specific expression. We leveraged single cell RNA sequencing (scRNA-seq) data of cells sampled from the mouse nervous system ${ }^{73}$ to identify cell-type specific RNA expression. Zeisel et al. ${ }^{73}$ sequenced cells obtained from 19 regions in the contiguous anatomical regions in the peripheral sensory, enteric, and sympathetic nervous system. After initial QC, Zeisel et al. retained 492,949 cells, which were sampled down to 160,796 high quality cells. These cells were further grouped into clusters representing 265 broad cell-types. We analyzed the dataset published by Zeisel et al. containing mean transcript counts for all genes with count $>1$ for each of the 265 clusters (Supplementary 
Table 11). We restricted analysis to genes with expression levels above the $25^{\text {th }}$ percentile. For each gene in each cell-type, we computed the cell-type specific proportion of reads for the gene (normalizing the expression within cell-type). We then computed the proportion of proportions over the 265 cell-types (computing the specificity of the gene to a specific celltype). We ranked the 12,119 genes retained in terms of specificity to each cell-type and then retained the $10 \%$ of genes most specific to a cell-type as the "cell-type specific" gene-set. We then tested whether any of the 265 cell-type specific gene-sets were enriched in the $\operatorname{Cog}$ or NonCog GWAS. This analysis sought to identify specific cell-types and specific regions in the brain involved in the etiology of $\operatorname{Cog}$ and $\operatorname{Non} \operatorname{Cog}$. We further computed the difference in enrichment for $\operatorname{Cog}$ and NonCog to test if any cell types were specific to either trait. For these analyses, we leveraged two widely used enrichment analysis tools: MAGMA ${ }^{71}$ and stratified LD score regression ${ }^{72}$ with the European reference panel from 1000 Genomes Project Phase 3 as SNP location and LD structure reference, Gencode release 19 as gene location reference and the human-mouse homology reference from MGI (http://www.informatics.jax.org/downloads/reports/HOM_MouseHumanSequence.rpt).

MAGMA. We used MAGMA (v1.07b $\left.{ }^{71}\right)$, a program for gene-set analysis based on GWAS summary statistics. We computed gene-level association statistics using a window of $10 \mathrm{~kb}$ around the gene for both $\operatorname{Cog}$ and NonCog. We then used MAGMA to run a competitive gene-set analysis, using the gene p-values and gene correlation matrix (reflecting LD structure) produced in the gene-level analysis. The competitive gene-set analysis tests whether the genes within the cell-type-specific gene-set described above are more strongly associated with Cog/NonCog than other genes.

Stratified LDscore regression. We used LD-score regression to compute LD scores for the SNPs in each of our "cell-type specific" gene-sets. Parallel to MAGMA analysis, we added a $10 \mathrm{~kb}$ window around each gene. We ran partitioned LD-score regression to compute 
the contribution of each gene-set to the heritability of Cog and NonCog. To guard against inflation, we use LD score best practices, and include the LD score baseline model (baselineL2.v2.2) in the analysis. We judged the statistical significance of the enrichment based on the p-value associated with the tau coefficient.

Difference in enrichment between $\operatorname{Cog}$ and NonCog. To compute differences in enrichment we compute a standardized difference between the per-annotation enrichment for Cog and NonCog as:

$$
Z_{\text {diff }}=\frac{e_{\operatorname{Cog}}-e_{\text {NonCog }}}{\operatorname{sqrt}\left(s e_{\operatorname{Cog}}^{2}+s e_{\text {NonCog }}^{2}-2 * C T I * s e_{\operatorname{Cog}} * s e_{\text {NonCog }}\right)}
$$

Where $e_{\operatorname{Cog}}$ is the enrichment of a particular gene-set for $\operatorname{Cog}, e_{N o n \operatorname{Cog}}$ is the enrichment for the same gene-set for NonCog, $s e_{\operatorname{Cog}}$ is the standard error of the enrichment for $\operatorname{Cog}$, $s e_{\text {NonCog }}$ is the standard error of the enrichment for NonCog, and CTI is the LD score crosstrait intercept, a metric of dependence between the GWASs of Cog and NonCog.

Enrichment of gene expression in the brain. We performed a transcriptome-wide association study (TWAS) using Gusev et al. ${ }^{74}$ (FUSION:

http://gusevlab.org/projects/fusion/). We used pre-computed brain-gene-expression weights available on the FUSION website, generated from 452 human individuals as part of the CommonMind Consortium. We then superimposed the bivariate distribution of the results of the TWAS for $\operatorname{Cog}$ and NonCog over the bivariate distribution expected given the sample overlap between EA and CP (the GWAS on which our GWAS of Cog and NonCog are based, see Supplementary Note 6).

\section{Brain modalities}


Brain volumes. We conducted genetic correlation analysis of brain volumes using GWAS results published by Zhao et al. ${ }^{77}$. Zhao et al. performed GWAS of total brain volume and 100 regional brain volumes, including 99 gray matter volumes and total white matter volume (Supplementary Table 16). Analyses included covariate adjustment for sex, age, their square interaction and 20 principle components. Analyses of regional brain volumes additionally included covariate adjustment for total brain volume. GWAS summary statistics for these 101 brain volumes were obtained from https://med.sites.unc.edu/bigs $2 /$ data/gwas-

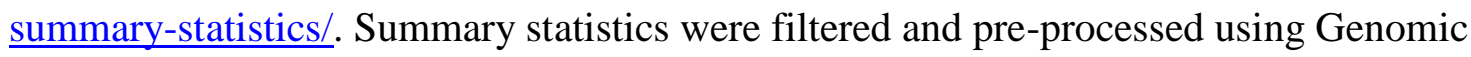
SEM's "munge" function, retaining all HapMap3 SNPs with allele frequency $>.01$ outside the MHC region. We used Genomic-SEM to compute the genetic correlations between $C o g$, NonCog and brain volumes. Analyses of regional volumes controlled for total brain volume. For each volume, we tested if correlations differed between $\operatorname{Cog}$ and NonCog. Specifically, we used a chi-squared test to evaluate the null hypothesis that the two genetic correlations were equal. We used FDR adjustment to correct for multiple testing. The FDR adjustment is applied to the results for all gray matter volumes for Cog and NonCog separately.

White matter structures. We conducted genetic-correlation analysis of white-matter structures using GWAS results published by Zhao et al. ${ }^{78}$. Zhao et al. performed GWAS of diffusion tensor imaging (DTI) measures of the integrity of white-matter tracts. DTI parameters were derived for fractional anisotropy (FA), mean diffusivity (MD), axial diffusivity (AD), radial diffusivity (RD), and mode of anisotropy (MO). Each of these parameters were measured for 22 white matter tracts of interests (Supplementary Table 17) resulting in 110 GWAS. GWAS summary statistics for these 110 GWAS were obtained from https://med.sites.unc.edu/bigs2/data/gwas-summary-statistics/. Summary statistics were filtered and processed using Genomic SEM's “munge” function; retaining all HapMap3 SNPs with allele frequency >.01 outside the MHC region. For each white matter structure, we 
tested if genetic correlations differed between $\operatorname{Cog}$ and NonCog. Specifically, we used a chisquared test to evaluate the null hypothesis that the two genetic correlations were equal. We used FDR adjustment to correct for multiple testing. As these different diffusion parameters are statistically and logically interdependent, having been derived from the same tensor, FDR adjustment was applied to the results for each type of white matter diffusion parameter separately. FDR correction was applied separately for Cog and NonCog.

\section{Additional Resource}

A FAQ on why, how and what we studied is available here:

https://medium.com/@kph3k/investigating-the-genetic-architecture-of-non-cognitive-skillsusing-gwas-by-subtraction-b8743773ce44

\section{Code availability}

Code used to run the analyses is available at: https://github.com/PerlineDemange/non$\underline{\text { cognitive }}$

A tutorial on how to perform GWAS-by-subtraction: http://rpubs.com/MichelNivard/565885 All additional software used to perform these analyses are available online.

\section{Data Availability}

GWAS summary data for NonCog \& $\operatorname{Cog}$ (excluding 23andMe) are available at: https://www.dropbox.com/s/cvzcedsfhbznv36/GWAS_sumstats_Cog_NonCog_Demange_et al.zip?dl=0.

For 23AndMe dataset access, see https://research.23andme.com/dataset-access/.

Part of the National Longitudinal Study of Adolescent to Adult Health (Add Health) data is publicly available and can be downloaded at the following link: 
https://data.cpc.unc.edu/projects/2/view\#public_li. For restricted access data, details of the data sharing agreement and data access requirements can be found at the following link: https://data.cpc.unc.edu/projects/2/view

The Dunedin study datasets reported in the current article are not publicly available due to lack of informed consent and ethical approval, but are available on request by qualified scientists. Requests require a concept paper describing the purpose of data access, ethical approval at the applicant's university, and provision for secure data access. We offer secure access on the Duke, Otago and King's College campuses. All data analysis scripts and results files are available for review. https://moffittcaspi.trinity.duke.edu/research-topics/dunedin

The E-Risk Longitudinal Twin Study datasets reported in the current article are not publicly available due to lack of informed consent and ethical approval, but are available on request by qualified scientists. Requests require a concept paper describing the purpose of data access, ethical approval at the applicant's university, and provision for secure data access. We offer secure access on the Duke and King's College campuses. All data analysis scripts and results files are available for review. https://moffittcaspi.trinity.duke.edu/research-topics/erisk

Netherlands Twin Register data may be accessed, upon approval of the data access committee, email: ntr.datamanagement.fgb@vu.nl.

Researchers will be able to obtain Texas Twins data through managed access. Requests for managed access should be sent to Dr. Elliot Tucker-Drob (tuckerdrob@uexas.edu) and Dr. Paige Harden (harden@utexas.edu), joint principal investigators of the Texas Twin Project. Wisconsin Longitudinal study data can be requested following this form: https://www.ssc.wisc.edu/wlsresearch/data/Request_Genetic_Data_28_June_2017.pdf 


\section{References}

1. Moffitt, T. E. et al. A gradient of childhood self-control predicts health, wealth, and public safety. Proc. Natl. Acad. Sci. 108, 2693-2698 (2011).

2. von Stumm, S., Hell, B. \& Chamorro-Premuzic, T. The Hungry Mind: Intellectual Curiosity Is the Third Pillar of Academic Performance. Perspect. Psychol. Sci. 6, 574-588 (2011).

3. Tucker-Drob, E. M., Briley, D. A., Engelhardt, L. E., Mann, F. D. \& Harden, K. P. Genetically-mediated associations between measures of childhood character and academic achievement. J. Pers. Soc. Psychol. 111, 790-815 (2016).

4. Heckman, J. J., Stixrud, J. \& Urzua, S. The Effects of Cognitive and Noncognitive Abilities on Labor Market Outcomes and Social Behavior. J. Labor Econ. 24, 411-482 (2006).

5. Heckman, J. J., Moon, S. H., Pinto, R., Savelyev, P. A. \& Yavitz, A. The rate of return to the HighScope Perry Preschool Program. J. Public Econ. 94, 114-128 (2010).

6. Conti, G., Heckman, J. J. \& Pinto, R. The Effects of Two Influential Early Childhood Interventions on Health and Healthy Behaviour. Econ. J. 126, F28-F65 (2016).

7. Gutman, L. M. \& Schoon, I. The impact of non-cognitive skills on outcomes for young people. Educ. Endow. Found. 59, 2019 (2013).

8. Garcia, E. The Need to Address Noncognitive Skills in the Education Policy Agenda. https://www.epi.org/publication/the-need-to-address-noncognitive-skills-in-theeducation-policy-agenda/ (2014).

9. Kautz, T., Heckman, J. J., Diris, R., Ter Weel, B. \& Borghans, L. Fostering and Measuring Skills: Improving Cognitive and Non-Cognitive Skills to Promote Lifetime Success.” OECD Education Working Papers, No. 110, OECD Publishing, Paris. (2014).

10. Heckman, J. J. Skill Formation and the Economics of Investing in Disadvantaged Children. LIFE CYCLES 312, 4 (2006). 
11. Heckman, J. J. \& Kautz, T. Hard evidence on soft skills. Labour Econ. 19, 451-464 (2012).

12. Rimfeld, K., Kovas, Y., Dale, P. S. \& Plomin, R. True grit and genetics: Predicting academic achievement from personality. J. Pers. Soc. Psychol. 111, 780-789 (2016).

13. Richardson, M., Abraham, C. \& Bond, R. Psychological correlates of university students' academic performance: A systematic review and meta-analysis. Psychol. Bull. 138, 353387 (2012).

14. Smithers, L. G. et al. A systematic review and meta-analysis of effects of early life noncognitive skills on academic, psychosocial, cognitive and health outcomes. Nat. Hum. Behav. 2, 867-880 (2018).

15. Kovas, Y. et al. Why children differ in motivation to learn: Insights from over 13,000 twins from 6 countries. Personal. Individ. Differ. 80, 51-63 (2015).

16. Loehlin, J. C. Genes and environment in personality development. (Sage Publications, 1992).

17. Tucker-Drob, E. M. \& Harden, K. P. Learning motivation mediates gene-bysocioeconomic status interaction on mathematics achievement in early childhood. Learn. Individ. Differ. 22, 37-45 (2012).

18. Malanchini, M., Engelhardt, L. E., Grotzinger, A. D., Harden, K. P. \& Tucker-Drob, E. M. "Same but different": Associations between multiple aspects of self-regulation, cognition, and academic abilities. J. Pers. Soc. Psychol. 117, 1164-1188 (2019).

19. Morris, T. T., Smith, G. D., van Den Berg, G. \& Davies, N. M. Investigating the longitudinal consistency and genetic architecture of non-cognitive skills, and their relation to educational attainment. http://biorxiv.org/lookup/doi/10.1101/470682 (2018) doi:10.1101/470682.

20. Liu, J. Z., Erlich, Y. \& Pickrell, J. K. Case-control association mapping by proxy using family history of disease. Nat. Genet. 49, 325-331 (2017). 
21. Bowles, S. \& Gintis, H. Schooling In Capitalist America: Educational Reform And The Contradictions Of Economic Life. (Basic Books, 1977).

22. Heckman, J. J. \& Rubinstein, Y. The Importance of Noncognitive Skills: Lessons from the GED Testing Program. Am. Econ. Rev. 91, 145-149 (2001).

23. Grotzinger, A. D. et al. Genomic structural equation modelling provides insights into the multivariate genetic architecture of complex traits. Nat. Hum. Behav. 3, 513 (2019).

24. Lee, J. J. et al. Gene discovery and polygenic prediction from a genome-wide association study of educational attainment in 1.1 million individuals. Nat. Genet. 50, 1112-1121 (2018).

25. Belsky, D. W. \& Harden, K. P. Phenotypic Annotation: Using Polygenic Scores to Translate Discoveries from Genome-Wide Association Studies from the Top-Down. Curr. Dir. Psychol. Sci. (in press).

26. Bulik-Sullivan, B. K. et al. LD Score regression distinguishes confounding from polygenicity in genome-wide association studies. Nat. Genet. 47, 291-295 (2015).

27. Ligthart, L. et al. The Netherlands Twin Register: Longitudinal Research Based on Twin and Twin-Family Designs. Twin Res. Hum. Genet. 1-14 (2019) doi:10.1017/thg.2019.93.

28. Harris, K. M. et al. Cohort Profile: The National Longitudinal Study of Adolescent to Adult Health (Add Health). Int. J. Epidemiol. 48, 1415-1415k (2019).

29. Poulton, R., Moffitt, T. E. \& Silva, P. A. The Dunedin Multidisciplinary Health and Development Study: overview of the first 40 years, with an eye to the future. Soc. Psychiatry Psychiatr. Epidemiol. 50, 679-693 (2015).

30. Moffitt, T. E. \& E-risk Team. Teen-aged mothers in contemporary Britain. J. Child Psychol. Psychiatry 43, 727-742 (2002).

31. Herd, P., Carr, D. \& Roan, C. Cohort profile: Wisconsin longitudinal study (WLS). Int. J. Epidemiol. 43, 34-41 (2014). 
32. Harden, K. P., Tucker-Drob, E. M. \& Tackett, J. L. The Texas Twin Project. Twin Res. Hum. Genet. 16, 385-390 (2013).

33. Benyamin, B. et al. Childhood intelligence is heritable, highly polygenic and associated with FNBP1L. Mol. Psychiatry 19, 253-258 (2014).

34. Chetty, R. et al. The Association Between Income and Life Expectancy in the United States, 2001-2014. JAMA 315, 1750 (2016).

35. Case, A. \& Deaton, A. Mortality and Morbidity in the 21st Century. Brook. Pap. Econ. Act. 2017, 397-476 (2017).

36. Hill, W. D. et al. Molecular Genetic Contributions to Social Deprivation and Household Income in UK Biobank. Curr. Biol. 26, 3083-3089 (2016).

37. Timmers, P. R. et al. Genomics of 1 million parent lifespans implicates novel pathways and common diseases and distinguishes survival chances. eLife 8, e39856 (2019).

38. Almlund, M., Duckworth, A. L., Heckman, J. \& Kautz, T. Personality Psychology and Economics. in Handbook of the Economics of Education vol. 4 1-181 (Elsevier, 2011).

39. Borghans, L., Duckworth, A. L. \& Heckman, J. J. The Economics and Psychology of Personality Traits. 88.

40. Rabin, M. A perspective on psychology and economics. Eur. Econ. Rev. 29 (2002).

41. Becker, A., Deckers, T., Dohmen, T., Falk, A. \& Kosse, F. The Relationship Between Economic Preferences and Psychological Personality Measures. Annu. Rev. Econ. 4, 453478 (2012).

42. Linnér, R. K. et al. Genome-wide association analyses of risk tolerance and risky behaviors in over 1 million individuals identify hundreds of loci and shared genetic influences. Nat. Genet. 51, 245-257 (2019).

43. Sanchez-Roige, S. et al. Genome-wide association study of delay discounting in 23,217 adult research participants of European ancestry. Nat. Neurosci. 21, 16-18 (2018). 
44. Yengo, L. et al. Meta-analysis of genome-wide association studies for height and body mass index in $~ 700000$ individuals of European ancestry. Hum. Mol. Genet. 27, 36413649 (2018).

45. Furberg, H., Kim, Y., Dackor, J. \& Boerwinckle, E. Genome-wide meta-analyses identify multiple loci associated with smoking behavior. Nat. Genet. 42, 441-447 (2010).

46. Walters, R. K. et al. Trans-ancestral GWAS of alcohol dependence reveals common genetic underpinnings with psychiatric disorders. 34 .

47. Schumann, G. et al. KLB is associated with alcohol drinking, and its gene product $\beta$-Klotho is necessary for FGF21 regulation of alcohol preference. Proc. Natl. Acad. Sci. 113, 14372-14377 (2016).

48. Pasman, J. A. et al. GWAS of lifetime cannabis use reveals new risk loci, genetic overlap with psychiatric traits, and a causal effect of schizophrenia liability. Nat. Neurosci. 21, 1161-1170 (2018).

49. Linnér, R. K., Dick, D. \& Koellinger, P. D. the Externalizing Consortium - Multivariate analyses of large-scale GWAS to identify genetic factors in externalizing behaviors and disorders. (2018) doi:None.

50. Barban, N. et al. Genome-wide analysis identifies 12 loci influencing human reproductive behavior. Nat. Genet. 48, 1462-1472 (2016).

51. Lo, M.-T. et al. Genome-wide analyses for personality traits identify six genomic loci and show correlations with psychiatric disorders. Nat. Genet. 49, 152-156 (2017).

52. John, O. P., Naumann, L. P. \& Soto, C. J. Paradigm shift to the integrative Big Five Trait taxonomy. Handb. Personal. Theory Res. 114-158 (2008) doi:10.1016/S01918869(97)81000-8.

53. de Moor, M. H. M. et al. Meta-analysis of genome-wide association studies for personality. Mol. Psychiatry 17, 337-349 (2012). 
54. Caspi, A., Roberts, B. W. \& Shiner, R. L. Personality development: stability and change. Annu. Rev. Psychol. 56, 453-484 (2005).

55. Kessler, R. C. et al. Social consequences of psychiatric disorders, I: educational attainment. Am. J. Psychiatry 1026-1032 (1995).

56. Breslau, J., Lane, M., Sampson, N. \& Kessler, R. C. Mental Disorders and Subsequent Educational Attainment in a US National Sample. J. Psychiatr. Res. 42, 708-716 (2008).

57. Power, R. A. et al. Polygenic risk scores for schizophrenia and bipolar disorder predict creativity. Nat. Neurosci. 18, 953-955 (2015).

58. Bansal, V. et al. Genome-wide association study results for educational attainment aid in identifying genetic heterogeneity of schizophrenia. Nat. Commun. Lond. 9, 1-12 (2018).

59. Wray, N. R. et al. Genome-wide association analyses identify 44 risk variants and refine the genetic architecture of major depression. Nat. Genet. 50, 668-681 (2018).

60. Ruderfer, D. M. et al. Genomic Dissection of Bipolar Disorder and Schizophrenia, Including 28 Subphenotypes. Cell 173, 1705-1715.e16 (2018).

61. Jansen, P. R. et al. Genome-wide analysis of insomnia in 1,331,010 individuals identifies new risk loci and functional pathways. Nat. Genet. 51, 394-403 (2019).

62. Duncan, L. et al. Significant Locus and Metabolic Genetic Correlations Revealed in Genome-Wide Association Study of Anorexia Nervosa. Am. J. Psychiatry 174, 850-858 (2017).

63. Grove, J. et al. Common risk variants identified in autism spectrum disorder. bioRxiv 224774 (2017) doi:10.1101/224774.

64. Arnold, P. D. et al. Revealing the complex genetic architecture of obsessive-compulsive disorder using meta-analysis. Mol. Psychiatry 23, 1181-1188 (2018).

65. Ripke, S. et al. Biological insights from 108 schizophrenia-associated genetic loci. Nature 511, 421-427 (2014). 
66. Bulik-Sullivan, B. et al. An Atlas of Genetic Correlations across Human Diseases and Traits. Nat. Genet. 47, 1236-1241 (2015).

67. Nieuwboer, H. A., Pool, R., Dolan, C. V., Boomsma, D. I. \& Nivard, M. G. GWIS: Genome-Wide Inferred Statistics for Functions of Multiple Phenotypes. Am. J. Hum. Genet. 99, 917-927 (2016).

68. The GTEx Consortium et al. The Genotype-Tissue Expression (GTEx) pilot analysis: Multitissue gene regulation in humans. Science 348, 648-660 (2015).

69. Pers, T. H. et al. Biological interpretation of genome-wide association studies using predicted gene functions. Nat. Commun. 6, 5890 (2015).

70. Fehrmann, R. S. N. et al. Gene expression analysis identifies global gene dosage sensitivity in cancer. Nat. Genet. 47, 115-125 (2015).

71. de Leeuw, C. A., Mooij, J. M., Heskes, T. \& Posthuma, D. MAGMA: Generalized GeneSet Analysis of GWAS Data. PLoS Comput. Biol. 11, 1-19 (2015).

72. Finucane, H. K. et al. Partitioning heritability by functional annotation using genome-wide association summary statistics. Nat. Genet. 47, 1228-1235 (2015).

73. Zeisel, A. et al. Molecular Architecture of the Mouse Nervous System. Cell 174, 9991014.e22 (2018).

74. Gusev, A. et al. Integrative approaches for large-scale transcriptome-wide association studies. Nat. Genet. 48, 245-252 (2016).

75. Nave, G., Jung, W. H., Karlsson Linnér, R., Kable, J. W. \& Koellinger, P. D. Are Bigger Brains Smarter? Evidence From a Large-Scale Preregistered Study. Psychol. Sci. 30, 4354 (2019).

76. Elliott, M. L. et al. A Polygenic Score for Higher Educational Attainment is Associated with Larger Brains. Cereb. Cortex 29, 3496-3504 (2019). 
77. Zhao, B. et al. GWAS of 19,629 individuals identifies novel genetic variants for regional brain volumes and refines their genetic co-architecture with cognitive and mental health traits. bioRxiv 586339 (2019) doi:10.1101/586339.

78. Zhao, B. et al. Large-scale GWAS reveals genetic architecture of brain white matter microstructure and genetic overlap with cognitive and mental health traits $(n=17,706)$. bioRxiv 288555 (2019) doi:10.1101/288555.

79. Haushofer, J. \& Fehr, E. On the psychology of poverty. Science 344, 862-867 (2014).

80. Briley, D. A., Domiteaux, M. \& Tucker-Drob, E. M. Achievement-relevant personality: Relations with the Big Five and validation of an efficient instrument. Learn. Individ. Differ. 32, 26-39 (2014).

81. Smoller, J. W. et al. Psychiatric genetics and the structure of psychopathology. Mol. Psychiatry 24, 409-420 (2019).

82. Plomin, R., Haworth, C. M. A. \& Davis, O. S. P. Common disorders are quantitative traits. Nat. Rev. Genet. 10, 872-878 (2009).

83. Meehl, P. E. Schizotaxia, schizotypy, schizophrenia. Am. Psychol. 17, 827-838 (1962).

84. von Stumm, S. \& Ackerman, P. L. Investment and intellect: A review and meta-analysis. Psychol. Bull. 139, 841-869 (2013).

85. Tucker-Drob, E. M. \& Harden, K. P. A Behavioral Genetic Perspective on Non-Cognitive Factors and Academic Achievement. in Genetics, Ethics and Education (eds. Grigorenko, E. L., Tan, M., Latham, S. R. \& Bouregy, S.) 134-158 (Cambridge University Press, 2017). doi:10.1017/9781316340301.007.

86. Tucker-Drob, E. M. Motivational factors as mechanisms of gene-environment transactions in cognitive development and academic achievement. in Handbook of competence and motivation: Theory and application, 2nd ed. 471-486 (The Guilford Press, 2017). 
87. Tucker-Drob, E. M. \& Harden, K. P. Intellectual Interest Mediates Gene $\times$ Socioeconomic Status Interaction on Adolescent Academic Achievement: Intellectual Interest and G×E. Child Dev. no-no (2012) doi:10.1111/j.1467-8624.2011.01721.x.

88. Malanchini, M. et al. Reading self-perceived ability, enjoyment and achievement: A genetically informative study of their reciprocal links over time. Dev. Psychol. 53, 698712 (2017).

89. Tropf, F. C. et al. Hidden heritability due to heterogeneity across seven populations. Nat. Hum. Behav. 1, 757-765 (2017).

90. Duncan, L. et al. Analysis of polygenic risk score usage and performance in diverse human populations. Nat. Commun. 10, 3328 (2019).

91. Martin, A. R. et al. Human Demographic History Impacts Genetic Risk Prediction across Diverse Populations. Am. J. Hum. Genet. 100, 635-649 (2017).

92. Willer, C. J., Li, Y. \& Abecasis, G. R. METAL: Fast and efficient meta-analysis of genomewide association scans. Bioinformatics 26, 2190-2191 (2010).

93. Willemsen, G. et al. The Adult Netherlands Twin Register: Twenty-Five Years of Survey and Biological Data Collection. Twin Res. Hum. Genet. 16, 271-281 (2013).

94. Highland, H. M., Avery, C. L., Duan, Q., Li, Y. \& Harris, K. M. Quality control analysis of Health GWAS data. https://www.cpc.unc.edu/projects/addhealth/documentation/guides/AH_GWAS_QC.pdf (2018).

95. Vilhjálmsson, B. J. et al. Modeling Linkage Disequilibrium Increases Accuracy of Polygenic Risk Scores. Am. J. Hum. Genet. 97, 576-592 (2015).

96. Finucane, H. K. et al. Heritability enrichment of specifically expressed genes identifies disease-relevant tissues and cell types. Nat. Genet. 50, 621-629 (2018). 


\section{Acknowledgements}

This study was developed with support from the Jacobs Foundation at a meeting organized by DWB and KPH with support from ETD and CM and also attended by coauthors PB, BWD, and JW. We gratefully acknowledge contributions to the meeting from Katrin Mannik and Felix Tropf, and the Jacobs Foundation Fellowship team who made the meeting possible. DWB, KPH, MGN, ETD, CM are fellows of the Foundation. JW is a Jacobs Foundation Young Scholar.

This study used GWAS summary statistics published by the Social Science Genetic Association Consortium and additional data obtained from 23andMe. We thank the research participants and employees of 23andMe for making this work possible. This study used data from the Netherlands Twin Register (NTR), the Texas Twin Study, the National Longitudinal Study of Adolescent to Adult Health (Add Health), the Dunedin Longitudinal Study, the ERisk Study, and the Wisconsin Longitudinal Study (WLS).

NTR is supported by: 'Twin-family database for behavior genetics and genomics studies' (NWO 480-04-004), Longitudinal data collection from teachers of Dutch twins and their siblings (NWO-481-08-011); Twin-family study of individual differences in school achievement (NWO 056-32-010) and Gravitation program of the Dutch Ministry of Education, Culture and Science and the Netherlands Organization for Scientific Research (NWO 0240-001-003); NWO Groot (480-15-001/674): Netherlands Twin Registry

Repository: researching the interplay between genome and environment; NWO- Spi-56-46414192 Biobanking and Biomolecular Resources Research Infrastructure (BBMRI - NL, 184.021.007 and 184.033.111); European Research Council (ERC-230374); the Avera Institute for Human Genetics, Sioux Falls, South Dakota (USA) and the National Institutes of Health (NIH, R01D0042157-01A); the NIMH Grand Opportunity grants (1RC2MH08995101 and 1RC2 MH089995-01). The Texas Twin Project is supported by Eunice Kennedy 
Shriver National Institute of Child Health and Human Development grants R01HD083613 and R01HD092548. Add Health is supported by Eunice Kennedy Shriver National Institute of Child Health and Human Development grant P01HD31921, and GWAS grants R01HD073342 and R01HD060726, with cooperative funding from 23 other federal agencies and foundations. The Dunedin Multidisciplinary Health and Development Study is supported by the NZ HRC, NZ MBIE, National Institute on Aging grant R01AG032282, and UK Medical Research Council grant MR/P005918/1. The E-Risk Study is supported by the UK Medical Research Council grant G1002190 and Eunice Kennedy Shriver National Institute of Child Health and Human Development grant R01HD077482. The Wisconsin Longitudinal Study is supported by National Institute on Aging grants R01AG041868 and P30AG017266.

Some of the work used a high-performance computing facility partially supported by grant 2016-IDG-1013 from the North Carolina Biotechnology Center. The Population Research Center at the University of Texas at Austin is supported by NIH grant P2CHD042849.

PAD is supported by the grant 531003014 from The Netherlands Organisation for Health Research and Development (ZonMW). PB is supported by the NORFACE-DIAL grant number 462-16-100. ETD is supported by NIH grants R01AG054628 and R01HD083613. AA is supported by the Foundation Volksbond Rotterdam. SRC is supported by the UK Medical Research Council grant MR/R024065/1 and NIH grant R01AG054628. BD is supported by award \# 96-17-04 from the Russell Sage Foundation and the Ford Foundation. DIB is supported by the Royal Netherlands Academy of Science (KNAW) Professor Award (PAH/6635). HFI was supported by the "Aggression in Children: Unraveling gene-environment interplay to inform Treatment and InterventiON strategies" project (ACTION). ACTION received funding from the European Union Seventh Framework Program (FP7/2007-2013) under grant agreement no 602768. EvB is supported by NWO 
VENI grant 451-15-017. KPH and ETD are Faculty Research Associates of the Population Research Center at the University of Texas at Austin, which is supported by grant, 5-R24HD042849, from the Eunice Kennedy Shriver National Institute of Child Health and Human Development (NICHD). MGN is supported by ZonMW grants 849200011 and 531003014 from The Netherlands Organisation for Health Research and Development, a VENI grant awarded by NWO (VI.Veni.191G.030). 


\section{List of Figures}

\section{Contents}

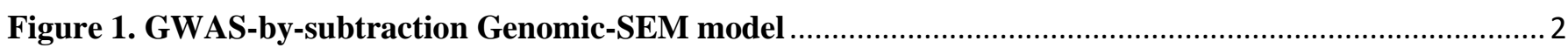

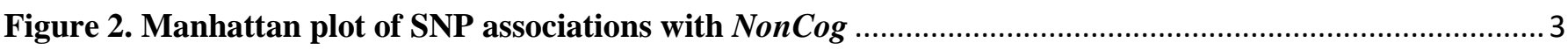

Figure 3. Polygenic prediction and genetic correlations with IQ and educational achievement ......................4

Figure 4. Estimates of genetic correlations with NonCog, Cog and Educational Attainment.......................... 5

Figure 5. Genetic correlations with regional gray matter volumes and white matter tracts ........................... 6 


\section{Figure 1. GWAS-by-subtraction Genomic-SEM model}

Cholesky model as fitted in Genomic SEM, with path estimates for a single SNP included as illustration. SNP, Cognitive performance (CP) and Educational attainment (EA) are observed variables based on GWAS summary statistics. The genetic covariance between CP and EA is estimated based on GWAS summary statistics for CP and EA. The model is fitted to a $3 \times 3$ observed variance-covariance matrix (i.e. SNP, CP, EA). Cog and Non-Cog are latent (unobserved) variables. The covariances between CP and EA and between Cog and NonCog are fixed to 0. The variance of the SNP is fixed to the value of $2 \mathrm{pq}$ ( $\mathrm{p}=$ reference allele frequency, $\mathrm{q}=$ alternative allele frequency, based on 1000 Genomes phase 3 ). The variances of $\mathrm{CP}$ and EA are fixed to 0 , so that all variance is explained by the latent factors. The variances of the latent factors are fixed to 1 . The observed variables $\mathrm{CP}$ and EA were regressed on the latent variables resulting in the estimates for the path loadings: $\lambda \operatorname{Cog}-\mathrm{CP}=.4465 ; \lambda \operatorname{Cog}-\mathrm{EA}=.2237 ; \lambda \operatorname{NonCog}-\mathrm{EA}=.2565$. The latent variables were then regressed on each SNP that met QC criteria.

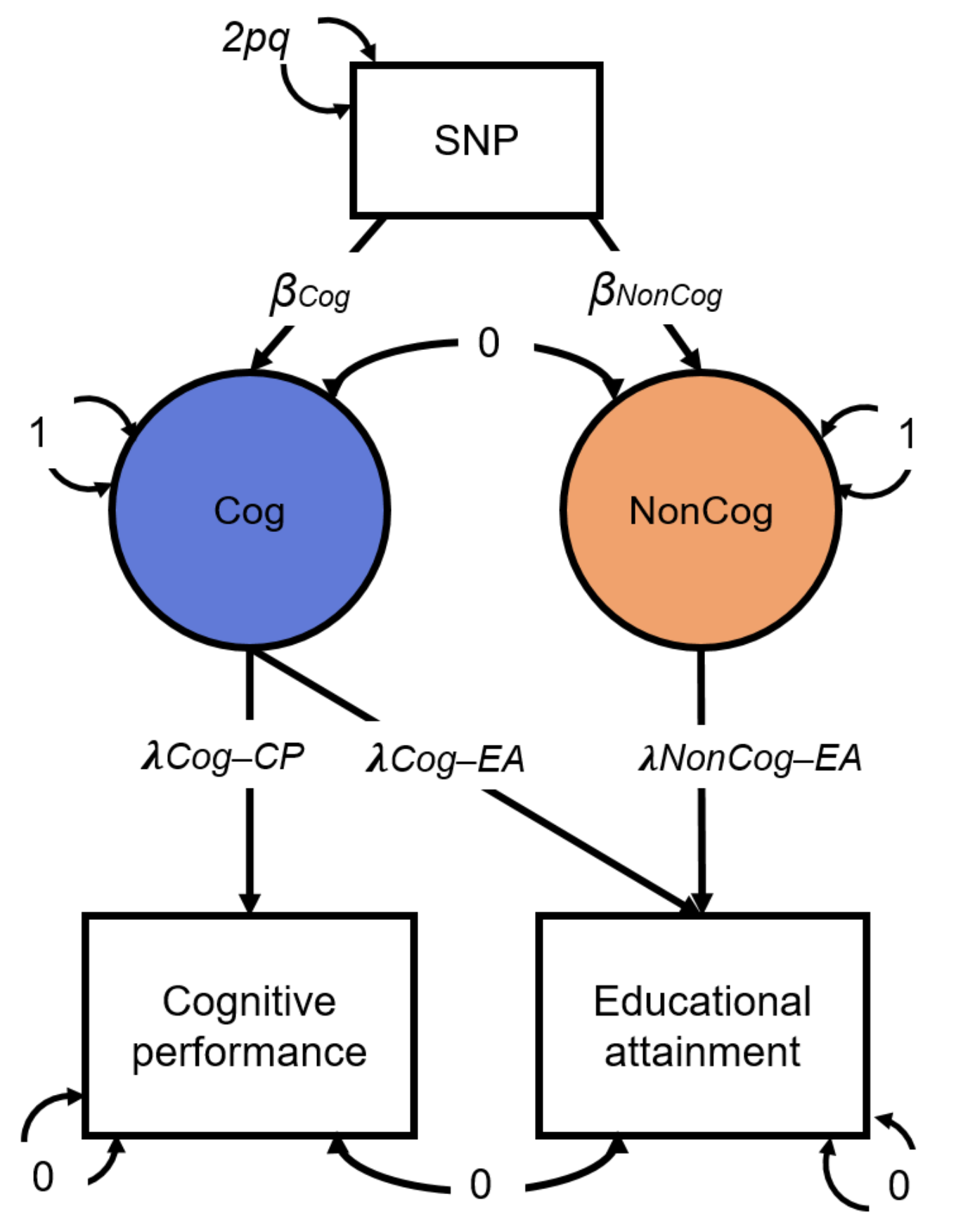


Plot of the $-\log _{10}\left(p\right.$-value) associated with the Wald test of $\beta_{\text {NonCog }}$ for all SNPs, ordered by chromosome and base position. Purple triangles indicate genome-wide significant $\left(p<5 \mathrm{e} 10^{-8}\right)$ and independent (within a 250Kb window and $\left.\mathrm{r}^{2}<.1\right)$ associations.

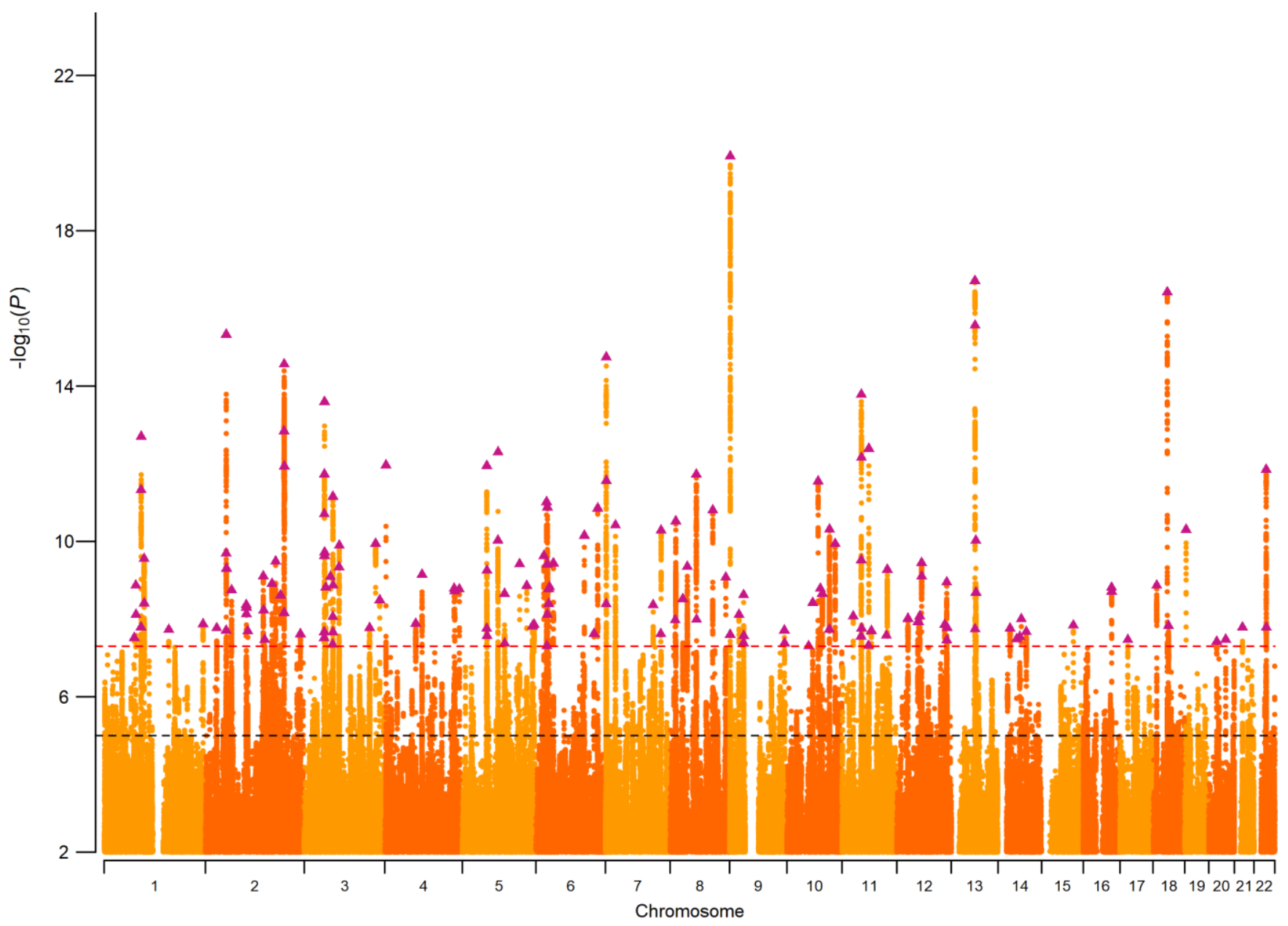


Figure 3. Polygenic prediction and genetic correlations with IQ and educational achievement

a. Genetic correlations of NonCog and Cog with Educational Attainment, Highest Math Class Taken, Selfreported Math Ability and Childhood IQ. Correlations with NonCog are in orange; with Cog in blue; with EA in gray. Genetic correlations were estimated using Genomic SEM. Error bars represent 95\% CIs. The difference test is based on a chi-squared test associated with a comparison between a model constraining these two correlations to be identical, versus a model where the correlations are freely estimated. For analysis of genetic correlations with educational attainment, we re-ran the Genomic-SEM model to compute NonCog and Cog using summary statistics that omitted the 23andMe sample from the educational attainment GWAS. We then used the 23andMe sample to run the GWAS of educational attainment. Thus, there is no sample overlap in this analysis.

b. Effect-size distributions from meta-analysis of NonCog and Cog polygenic score associations with cognitive test performance and educational attainment. Outcomes were regressed simultaneously on NonCog and Cog polygenic scores. Effect-sizes entered into the meta-analysis were standardized regression coefficients interpretable as Pearson $r$. Samples and measures are detailed in Supplementary Tables 4-5. Traits were measured in different samples: Educational Attainment was measured in the AddHealth, Dunedin, E-Risk, NTR and WLS samples $(\mathrm{N}=24,056)$; Reading Achievement and Mathematics Achievement were measured in the AddHealth, NTR, and Texas-Twin samples ( $N=9,274$ for reading achievement; $N=10,747$ for mathematics achievement); Cognitive test performance (IQ) was measured in the Dunedin, E-Risk, NTR, Texas Twins and WLS samples $(\mathrm{N}=11,351)$.

\section{a. Genetic Correlation Analysis}

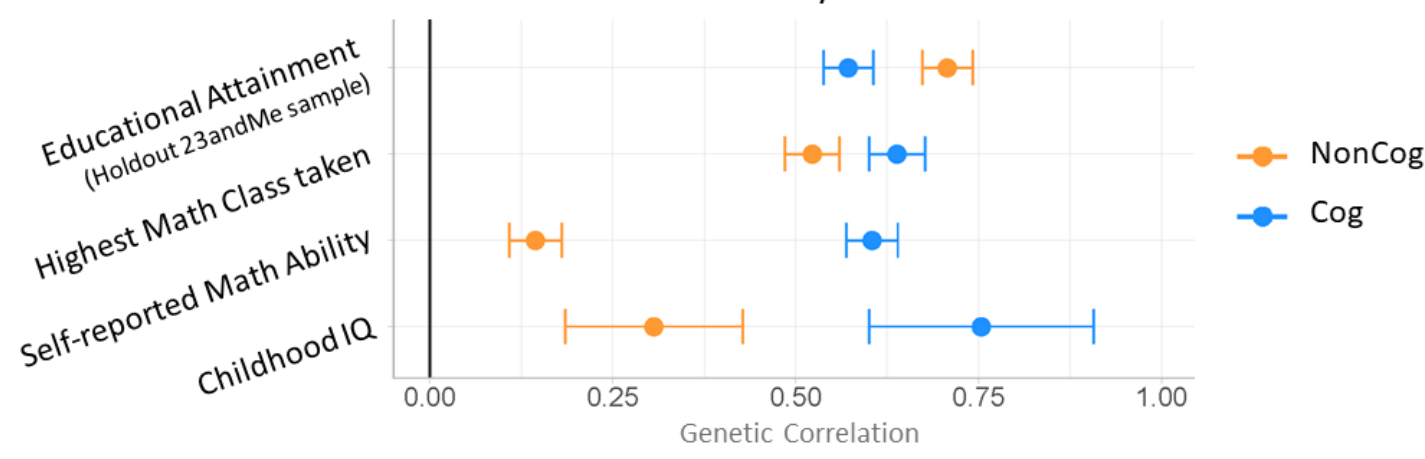

b. Polygenic Score Analysis

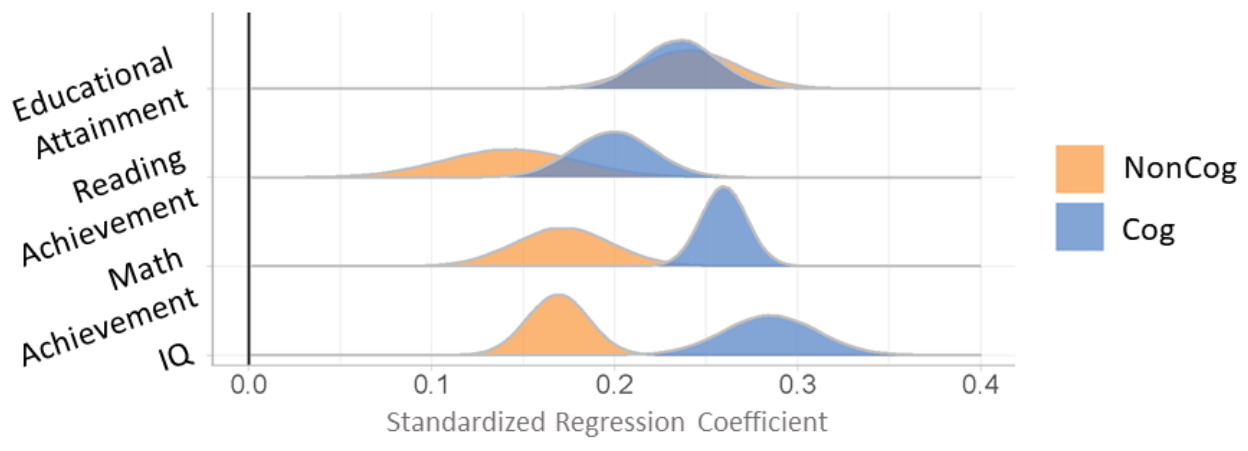




\section{Figure 4. Estimates of genetic correlations with $\mathrm{NonCog}, \mathrm{Cog}$ and Educational Attainment}

Genetic correlations of NonCog, Cog, and EA with selected phenotypes. NonCog genetic correlations are plotted in orange. Cog genetic correlations are plotted in blue. EA genetic correlations are plotted in gray. Genetic correlations were estimated in Genomic SEM. Error bars represent 95\% CIs. Red stars indicate a statistically significant (FDR corrected p-value < 0.05) difference in the magnitude of the correlation with NonCog versus Cog. The FDR correction was applied based on all genetic correlations tested (including in Supplementary Figure 2). The difference test is based on a chi-squared test associated with a comparison between a model constraining these two correlations to be identical, versus a model where the correlations are freely estimated. Source GWAS are listed in Supplementary Table 8.

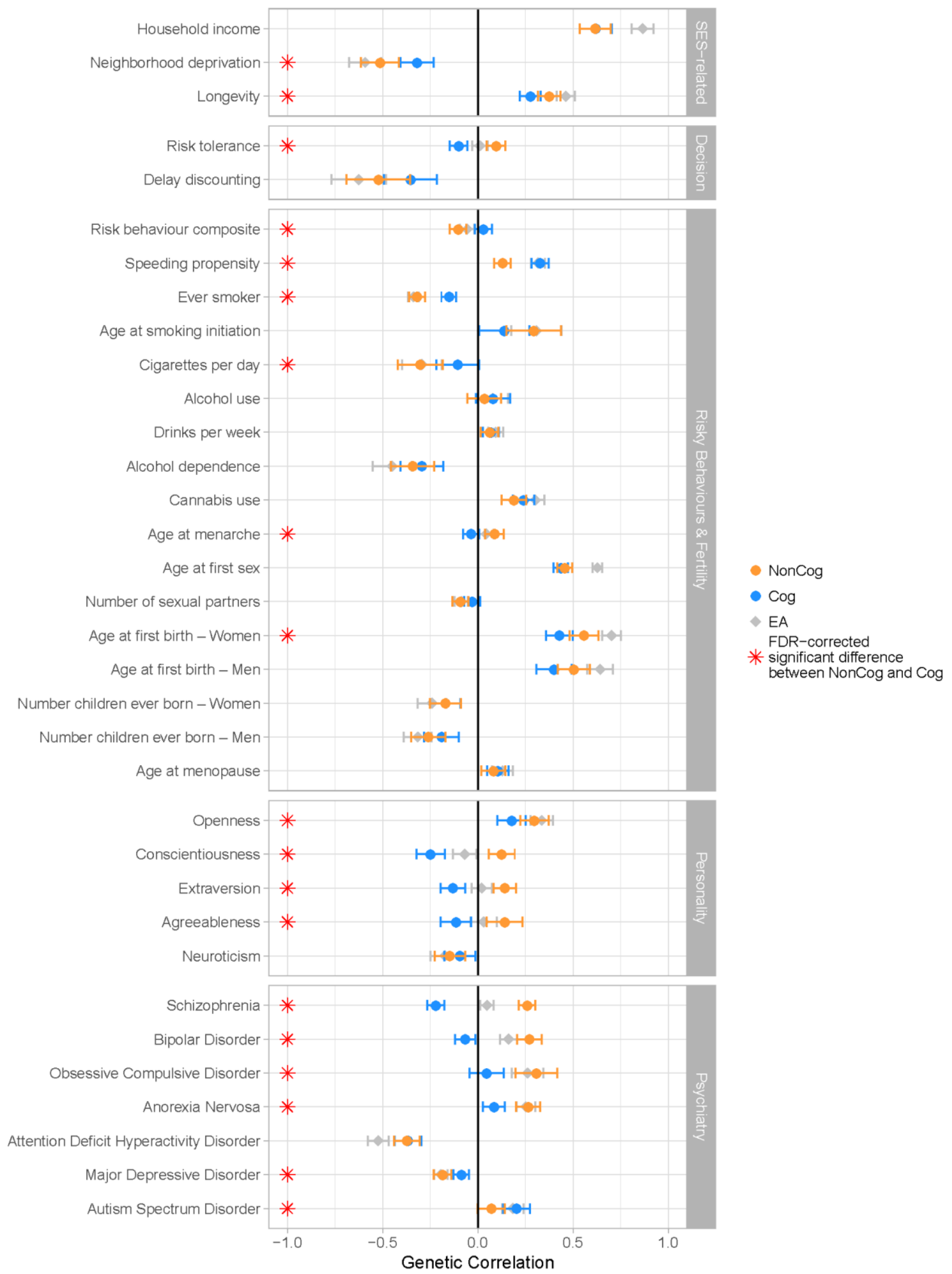




\section{Figure 5. Genetic correlations with regional gray matter volumes and white matter tracts}

a. Cortical patterning of FDR-corrected significant genetic correlations with regional gray matter volumes for $\operatorname{Cog}$ versus NonCog, after correction for total brain volume. Regions of interest are plotted according to the Desikan-KillianyTourville atlas, shown on a single manually-edited surface (Klein \& Tourville, 2012; http://mindboggle.info). Cog showed significant associations with gray matter volume for the bilateral fusiform, insula and posterior cingulate, the left superior temporal and left pericalcarine and right superior parietal volumes. NonCog was not associated with any of the regional brain volumes.

b. White matter tract patterning of FDR-corrected significant genetic correlations with regional mode of anisotropy (MO) for $\operatorname{Cog}$ versus NonCog. White matter tract probability maps are plotted according to the Johns Hopkins University DTI atlas (https://neurovault.org/). Cog was not associated with regional MO. NonCog showed significant associations with MO in the corticospinal tract, the retrolenticular limb of the internal capsule and the splenium of the corpus callosum.

a.

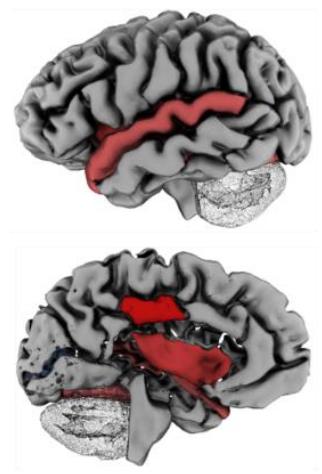

$\operatorname{Cog}$

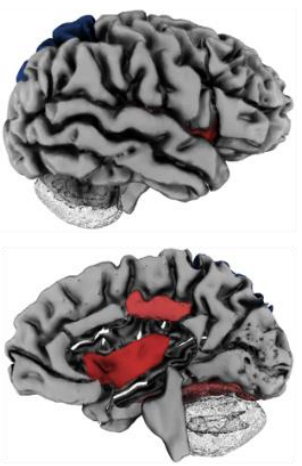

b.

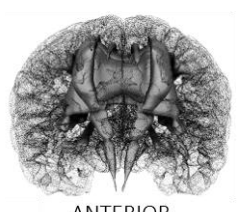

ANTERIOR

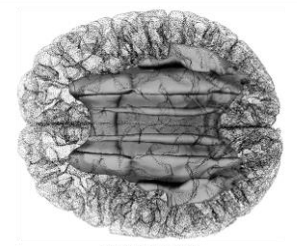

SUPERIOR
$\operatorname{Cog}$

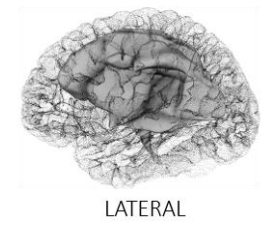

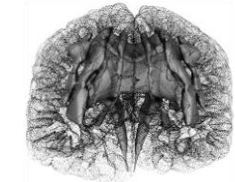

POSTERIOR

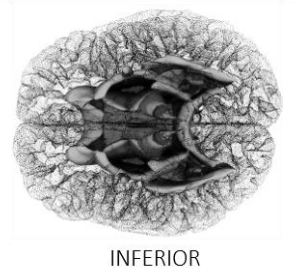

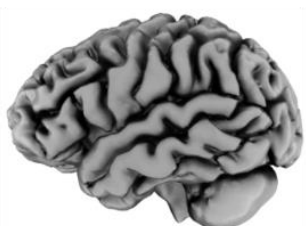
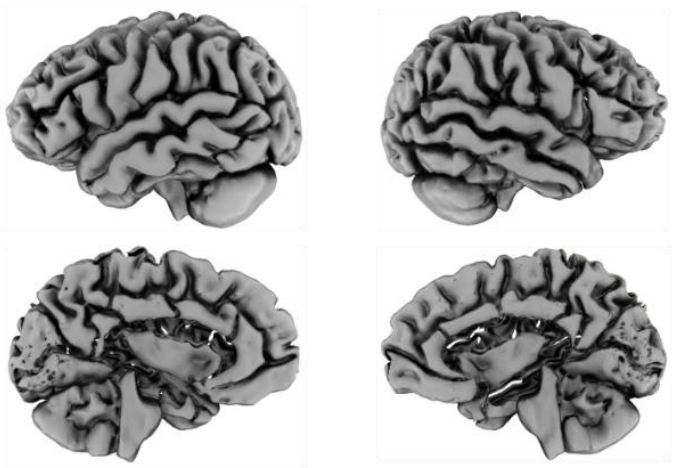

NonCog
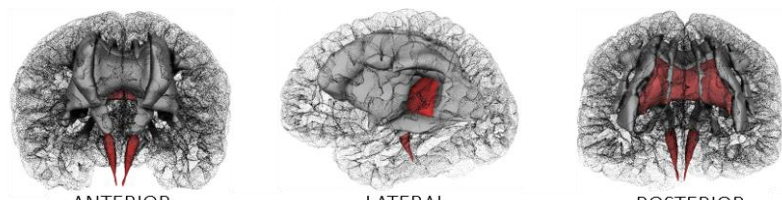

ANTERIOR

LATERAL
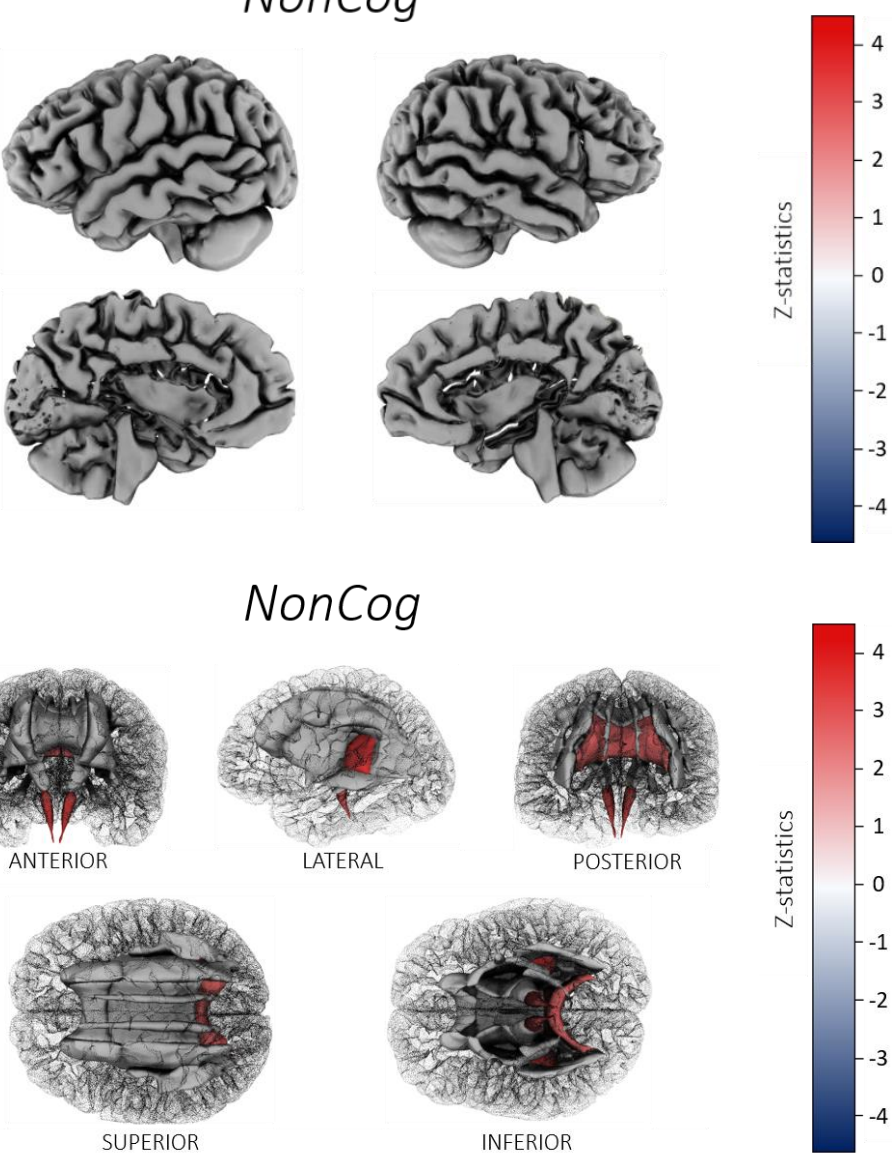